\title{
Innate resistance of PD-1 blockade through loss of function mutations in JAK resulting in inability to express PD-L1 upon interferon exposure
}

\author{
Daniel Shin ${ }^{*}$, Angel Garcia-Diaz ${ }^{1}$, Jesse Zaretsky², Helena Escuin-Ordinas', Siwen Hu-Lieskovan, \\ Nicolaos J Palaskas ${ }^{1}$, Willy Hugo ${ }^{1}$, Marie Sara Komenan ${ }^{1}$, Bartosz Chmielowski ${ }^{4}$, Grace Cherry ${ }^{1}$, Beata Berent-Maoz ${ }^{1}$, \\ Thomas G Graeber ${ }^{1}$, Roger Lo ${ }^{1}$, Begonya Comin-Anduix ${ }^{5}$, Antoni Ribas ${ }^{6}$
}

From 30th Annual Meeting and Associated Programs of the Society for Immunotherapy of Cancer (SITC 2015) National Harbor, MD, USA. 4-8 November 2015

\section{Introduction}

PD-L1-negative tumors assessed by immunohistochemistry often still respond to PD-1 blockade. PD-L1 is inducible by interferon, therefore, absolute negative tumors are the ones unable to up-regulate PD-L1 in response to interferons. Genetic mutations in the interferon receptor signaling pathway leading to loss of PDL1 up-regulation were hypothesized to exhibit innate resistance to PD-1 blockade.

\section{Experimental procedures}

After optimization, 50 primary human melanoma cell lines were exposed to interferons (alpha, beta and gamma) and PD-L1 expression was measured. Interferon signaling was assessed by single cell phospho-proteomics, pSTAT1 (Y701), pSTAT3, pSTAT5, pSTAT6 expression level by flow cytometry (FACS LSRII). Western blot assessed JAK1/JAK2/IRF1 as well as STAT/pSTAT expression and Whole exome sequencing was performed by next generation sequencing for three selected melanoma cell lines and on biopsies from 25 patients with advanced melanoma treated with anti-PD-1 therapy.

\section{Results}

Three out of 50 melanoma cell lines were unable to upregulate $\mathrm{PD}-\mathrm{L} 1$ in response to interferon gamma; two of them had disruptive mutations in JAK1 or JAK2, and a third one had a defect in expression of IRF1 in response to interferons. Western blot analysis confirmed loss of function for the JAK1/JAK2 mutations and loss of downstream IRF1/STAT1/3/5 phosphorylation events. Whole exome sequencing of biopsies from 15 patients with metastatic melanoma who had objective response to PD-1 blockade (pembrolizumab) showed no homozygous inactivating mutations in interferon signaling pathway genes. Interestingly, one patient with the highest mutational load out of 10 patients without clinical response to PD-1 blockade had an amplified allele of JAK1 with a P429S mutation in the src-homology (SH2) domain. A cell line derived from this patient showed lack of sustained up-regulating of PD-L1 expression in response to interferon gamma by, and Western blot confirmed loss of JAK1 expression. Immunohistochemistry of tumor biopsy for this patient showed few CD8+ $\mathrm{T}$ cells.

\section{Conclusions}

This study has defined genetic mechanisms of innate resistance to PD-1 blockade which lead to inhibition of adaptive PD-L1 expression in patients with advanced melanoma. This work suggests lack of interferon-gamma induced PD-L1 upregulation has the potential to be a negative selective marker for PD-1 blockade therapy.

\footnotetext{
Authors' details

${ }^{1}$ UCLA, Los Angeles, CA, USA. ²UCLA Molecular and Medical Pharmacology, Los Angeles, CA, USA. ${ }^{3}$ David Geffen School of Medicine at UCLA, Los Angeles, CA, USA. ${ }^{4}$ Division of Hematology - Medical Oncology, UCLA Jonsson Comprehensive Cancer Center, Los Angeles, CA, USA. ${ }^{5}$ UCLA, School of Medicine, LA, CA, USA. ${ }^{6}$ University of California at Los Angeles Medical
} Center, Los Angeles, CA, USA.

Published: 4 November 2015 
doi:10.1186/2051-1426-3-S2-P311

Cite this article as: Shin et al: Innate resistance of PD-1 blockade through loss of function mutations in JAK resulting in inability to express PD-L1 upon interferon exposure. Journal for ImmunoTherapy of Cancer 2015 3(Suppl 2):P311.

Submit your next manuscript to BioMed Central and take full advantage of:

- Convenient online submission

- Thorough peer review

- No space constraints or color figure charges

- Immediate publication on acceptance

- Inclusion in PubMed, CAS, Scopus and Google Scholar

- Research which is freely available for redistribution

Submit your manuscript at www.biomedcentral.com/submit 